University of Wollongong

Research Online

Faculty of Engineering - Papers (Archive)

Faculty of Engineering and Information

Sciences

December 2005

\title{
Seismic Lateral Response of Piles in Liquefying Soil
}

D. S. Liyanapathirana

University of Wollongong, saml@uow.edu.au

H. G. Poulos

University of Sydney

Follow this and additional works at: https://ro.uow.edu.au/engpapers

Part of the Engineering Commons

https://ro.uow.edu.au/engpapers/176

\section{Recommended Citation}

Liyanapathirana, D. S. and Poulos, H. G.: Seismic Lateral Response of Piles in Liquefying Soil 2005.

https://ro.uow.edu.au/engpapers/176

Research Online is the open access institutional repository for the University of Wollongong. For further information contact the UOW Library: research-pubs@uow.edu.au 


\title{
Seismic Lateral Response of Piles in Liquefying Soil
}

\author{
D. S. Liyanapathirana, M.ASCE, ${ }^{1}$ and H. G. Poulos, F.ASCE ${ }^{2}$
}

\begin{abstract}
Soil liquefaction is one of the major factors affecting the behavior of piles founded in seismically active areas. Although methods are available for seismic analysis of pile foundations, in many of them, the supporting soil is assumed to be an elastic material. Here a numerical model is presented which takes into account the reduction of soil stiffness and strength due to pore pressure generation and subsequent soil liquefaction, in addition to the material nonlinearity. Results obtained from the new method are compared with centrifuge test data and show excellent agreement with the observed pile behavior during these tests. To investigate the effects of soil liquefaction on the internal pile response, a parametric study is carried out for a range of material and geometric properties of the pile and surrounding soil. The effect of the nature of the earthquake on pile performance has been studied using 25 earthquake records scaled to different acceleration levels. It is shown that the "Arias intensity" and the natural frequency of the earthquake ground motion have a significant influence on the pile performance in liquefying soil. Existing elastic analysis methods for kinematic pile loading in layered soil deposits with soft and stiff layers are applied to the soil deposits with liquefying and nonliquefying layers. It is found that these simple design methods, which were derived assuming that the soil is a linear elastic material, do not predict bending moments accurately when nonlinear behavior of soil and effects of pore pressure generation are significant. Also a simplified limit equilibrium method proposed for the evaluation of bending response of single pile foundations subjected to lateral spreading is compared with the bending response obtained from the proposed numerical model. It is found that the limit equilibrium method, which is developed based on the centrifuge test results, does not give accurate results when the pile diameter and the thickness of the liquefied soil layer deviates from the values used for the centrifuge tests.
\end{abstract}

DOI: 10.1061/(ASCE)1090-0241(2005)131:12(1466)

CE Database subject headings: Pile foundations; Earthquake loads; Liquefaction; Seismic effects.

\section{Introduction}

The performance of piles in liquefying ground under earthquake loading is a complex problem due to the effects of progressive buildup of pore water pressures in the saturated soil. The loss of soil strength and stiffness due to liquefaction may develop large bending moments and shear forces in piles founded in liquefying soil, leading to pile damage. The significance of liquefactionrelated damage to pile foundations has been clearly demonstrated by the major earthquakes that have occurred during past years such as the 1964 Niigata, 1964 Alaska, 1989 Loma-Prieta, and 1995 Hyogoken-Nambu.

There remain many uncertainties in the mechanisms involved in pile-soil-structure interaction in liquefying soil, although the data recorded during the 1995 Hyogoken-Nambu earthquake, shake table tests (e.g., Ohtomo 1996; Tamura et al. 2000; Yasuda et al. 2000; Mizuno et al. 2000; Nakamura et al. 2000), and

${ }^{1}$ Senior Lecturer, Dept. of Civil, Mining and Environmental Engineering, Univ. of Wollongong, Northfields Ave., Wollongong, NSW 2522, Australia.

${ }^{2}$ Senior Principal, Coffey Geosciences Pty. Ltd. and Emeritus Professor of Civil Engineering, Dept. of Civil Engineering (J05), Univ. of Sydney, Sydney, NSW 2006, Australia.

Note. Discussion open until May 1, 2006. Separate discussions must be submitted for individual papers. To extend the closing date by one month, a written request must be filed with the ASCE Managing Editor. The manuscript for this paper was submitted for review and possible publication on November 12, 2002; approved on August 16, 2004. This paper is part of the Journal of Geotechnical and Geoenvironmental Engineering, Vol. 131, No. 12, December 1, 2005. CASCE, ISSN 10900241/2005/12-1466-1479/\$25.00. centrifuge tests (e.g., Dobry et al. 1995; Abdoun et al. 1997; Horikoshi et al. 1998; Wilson et al. 1999; Wilson et al. 2000) provide an insight into the mechanism of pile-soil-structure interaction in liquefying soil.

Numerical procedures for the analysis of piles founded in liquefying soil have large uncertainties due to lack of understanding of the mechanisms involved in soil-pile interaction in the liquefying soil. Although numerical models based on two-dimensional and three-dimensional finite element analyses (e.g., Hamada et al. 1994; Sakajo et al. 1995; Zheng et al. 1996; Shahrour and Ousta 1998; Finn et al. 2001) provide better insights into this interaction, they are computationally complex and time-consuming. Therefore in recent years, one-dimensional Winkler models based on finite element and finite difference methods for the seismic analysis of pile foundations have become popular amongst designers. In Winkler models, the pile is modeled as a beam and the lateral soil pressure acting on the pile is modeled using a nonlinear spring-dashpot model. These methods are computationally very efficient and give results in a very short time.

In Winkler models, a $p$ - $y$ curve is used to define the behavior of the nonlinear spring at any depth, where $p=$ soil resistance per unit length of the pile and $y=$ pile lateral displacement. These $p-y$ curves should be back-figured from the field or model tests. However, for liquefying soil, available case histories and experimental data are limited. Therefore this paper presents a method based on Mindlin's equation to determine the nonlinear spring constants of the Winkler model. Depending on the amount of pore pressure development, spring coefficients in the spring-dashpot model are degraded. The effect of radiation damping is taken into account separately. This is an extension of the method developed 
by Poulos (1982) for piles subjected to lateral soil movements under static conditions.

\section{Numerical Mode}

The one-dimensional numerical model developed for the analysis of piles founded in liquefying soil is based on the finite element method and involves two stages. First, an effective stress based free-field ground response analysis is carried out to determine the external soil movement and the degradation of soil stiffness and strength due to pore pressure generation. Second, a seismic analysis of the pile is carried out by applying computed ground displacements dynamically to the pile. For the pile analysis, the soil shear modulus and ultimate lateral strength are calculated based on the effective stress level of the soil.

\section{Ground Response Analysis}

The ground response analysis is carried out by dividing the soil deposit into a number of layers. One-half of the mass of each layer is concentrated at the layer boundaries as shown in Fig. 1. The lumped masses in the layered system are connected by nonlinear springs with a hyperbolic stress-strain relationship, which reflects nonlinear, strain dependent and hysteretic behavior of soil. Input motions are applied to the lumped mass at the boundary between the soil deposit and the bedrock through a viscous dashpot with damping, $\rho_{B R} V_{B R}$, as shown in Fig. 1, where $\rho_{B R}$ and $V_{B R}$ denote the density and the shear wave velocity of the bedrock material, respectively. This viscous damping is included in the analysis to take into account the effect of energy loss due to the dispersion of wave energy (Joyner and Chen 1975).

Pore pressure generation is calculated based on the effective stress method developed by Liyanapathirana and Poulos (2002). During the analysis, soil stiffness and strength are degraded, dependent on the effective stress level of the soil. The time history of these values together with soil displacements are stored in a separate file and subsequently used to obtain the pile response in liquefying soil.

Although it is assumed that the liquefied soil does not have any stiffness, computationally it is difficult to obtain a stable solution with a near-zero shear modulus. By analyzing field data recorded at the Port Island site during the Kobe 1995 earthquake,
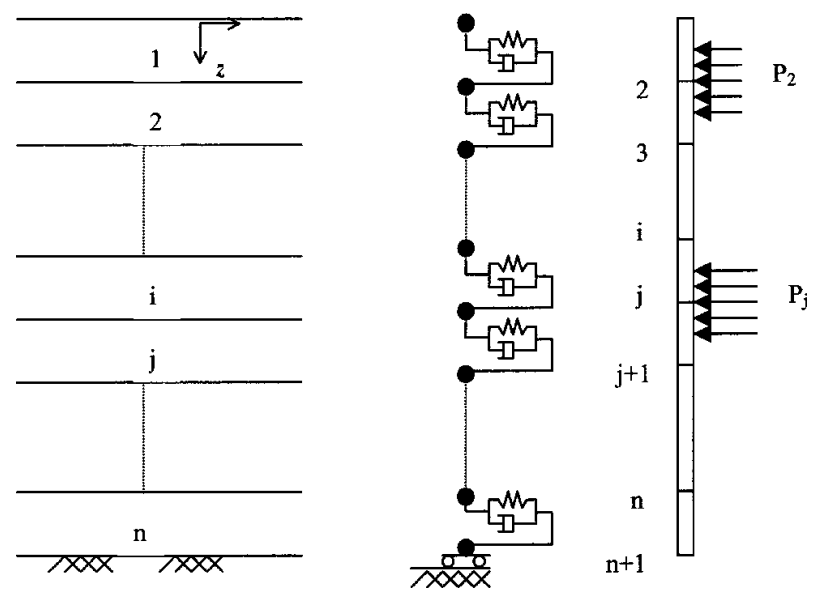

Fig. 1. Lumped mass representation of the discretized system

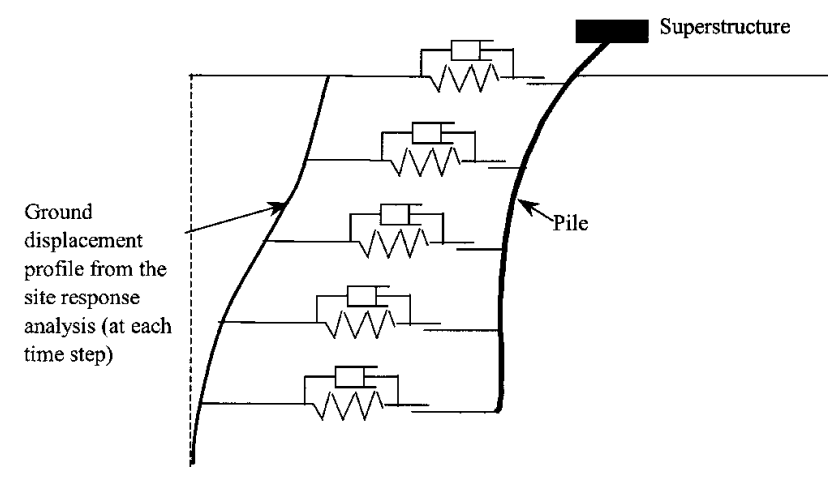

Fig. 2. Beam on Winkler foundation model for dynamic pile analysis

Davis and Berril (1998) reported that the shear wave velocity of the liquefied region is about $25 \mathrm{~m} / \mathrm{s}$. Ishihara and Towhata (1982) also suggested that since shear stress application during earthquakes is multidirectional, even when shear stresses are reduced to zero in one direction, there will always be some shear stress left in the soil. This was demonstrated in the rotational simple shear test performed by Ishihara and Yamasaki (1980). Therefore in the numerical studies performed in the following sections, a lower limit has been set at $2 \%$ of initial effective vertical stress, below which effective vertical stress is not allowed to decrease and pore pressures are not allowed to build up.

\section{Pile Analysis}

In the dynamic analysis of piles, moving soil interacts with the pile and in the vicinity of the pile, soil displacement is different from the displacement of the soil if there were no piles. Therefore in the pile analysis, it is assumed that the displacement of the soil away from the pile can be represented by the displacements obtained from the free field ground response analysis. Soil-pile interaction is modeled using the analysis method for a dynamically loaded beam on a nonlinear Winkler foundation, where the pile is modeled as a beam and the lateral pressure acting on the pile is modeled using a spring-dashpot model with a plastic slider to limit the ultimate lateral pressure at the pile-soil interface as shown in Fig. 2. In this model, displacement of the soil adjacent to the pile wall is represented by the displacement of the plastic slider, which is different from the displacement of the soil away from the pile.

The partial differential equation for a beam on a Winkler foundation is given by

$$
E_{P} I_{p}\left(\frac{\partial^{4} U_{p}}{\partial z^{4}}\right)+M_{p}\left(\frac{\partial^{2} U}{\partial t^{2}}\right)=K x\left(U_{f f}-U_{p}\right)+C_{x}\left(\frac{\partial U_{f f}}{\partial t}-\frac{\partial U_{p}}{\partial t}\right)
$$

where $E_{p}=$ Young's modulus of the pile material, $I_{p}=$ inertia of the pile, $U_{p}=$ pile displacement, $U_{f f}=$ free field lateral soil displacement, $M_{p}=$ mass of the pile, and $K_{x}$ and $C_{x}=$ spring and dashpot coefficients of the Winkler model. A solution to the problem can be obtained by solving Eq. (1) using the finite element method.

The spring coefficients of the Winkler model are obtained by integrating the Mindlin's equation over a rectangular area in the $y-z$ plane extending from $y=-d / 2$ to $+d / 2$ and $z=c_{2}$ to $c_{1}$ given by Douglas and Davis (1964), where $d=$ diameter of the pile. Then the displacement at any point in the rectangular area is given by 
Table 1. Material Properties for Nevada Sand (Popescu and Prevost 1993, Reprinted with Permission from Elsevier)

\begin{tabular}{lcc}
\hline & & Nevada sand \\
\cline { 2 - 3 } Property & $D_{r}=40 \%$ & $D_{r}=55 \%$ \\
\hline Mass density_solid $\left(\mathrm{kg} / \mathrm{m}^{3}\right)$ & $2,670.0$ & $D_{r}=80 \%$ \\
Porosity & 0.424 & $2,670.0$ \\
Low-strain shear modulus, $G_{0}(\mathrm{MPa})$ & $2,670.0$ & 0.406 \\
Reference mean effective normal stress $(\mathrm{kPa})$ & 100.0 & 28.0 \\
Friction angle, $\phi^{\prime}$ & $33^{\circ}$ & 100.0 \\
Permeability $(\mathrm{m} / \mathrm{s})$ & $6.6 \times 10^{-5}$ & $34.15^{\circ}$ \\
\end{tabular}

$$
U_{x=0}=\frac{p}{G} f\left(c_{1}, c_{2}, b, y, z, v\right)
$$

where $p=$ uniformly distributed load over the rectangular area, $\left(c_{1}-c_{2}\right) d, \nu=$ Poisson's ratio of the soil, and $G=$ shear modulus of the soil, which varies with time along the depth of the soil deposit due to pore pressure generation. If $U_{i j}$ represents the displacement at the centroid of the $i$ th rectangle due to a uniform pressure $p_{j}$ distributed over the $j$ th rectangle, then we can write

$$
U_{i j}=p_{j} F_{i j}
$$

where $F_{i j}$ is the influence coefficient determined from Eq. (2). Since the analysis is based on the finite element method, nodal displacements should be calculated along the pile. The displacement at node $i$ due to loading over the pile is given by

$$
U_{i}=p_{1} F_{i 1}+p_{2} F_{i 2}+\cdots+p_{j} F_{i j}+\cdots+p_{n} F_{i n}
$$

This can be written in matrix form as

$$
\{U\}=[F]\{p\}
$$

where $F=$ flexibility matrix of influence coefficients, which is calculated at $y=-d / 2,0$, and $+d / 2$ and the average value is obtained at the level of each pile node. The spring coefficients of the Winkler model which represent the interaction between the pile and soil are obtained by inverting $[F]$.

When using Mindlin's method, interaction between the spring coefficients along the pile is taken into account. Therefore the stiffness matrix which represents the interaction between the pile and soil is a nonsymmetric matrix of size $n \times n$, where $n=$ number of nodes along the pile. Due to the gradual increase in pore pressure level of the soil, the shear modulus of the soil changes with time. Therefore these spring coefficients should be calculated at the beginning of each time step during the analysis.

The Mindlin hypothesis does not automatically satisfy the soil radiation damping and this should be incorporated into the analysis separately. Here, the value of $5 \rho_{s} V_{s}$ proposed by Kaynia in 1988 (Tabesh and Poulos 2000) is used for the dashpot coefficient where $\rho_{s}=$ density of the soil and $V_{s}=$ shear wave velocity of the soil. This dashpot takes into account the radiation damping of the shear waves traveling away from the pile.

Time integration of Eq. (1) is performed using the constant average acceleration method. At each time step, the lateral pressure at the soil-pile interface is monitored and an iterative procedure is used to keep it at or below the ultimate lateral presssure at the pile-soil interface. When the lateral pressure at the pile-soil interface reaches the ultimate value, soil yielding occurs.

For piles in sand, Broms (1964) has suggested that the ultimate lateral pressure can be given by

$$
P_{y}=N_{p} \cdot P_{p}
$$

where $N_{p}$ =factor ranging between 3 and 5 , and $P_{p}=$ Rankine passive pressure given by

$$
P_{p}=\sigma_{v}^{\prime} \tan ^{2}\left(45+\phi^{\prime} / 2\right)
$$

where $\sigma_{v}^{\prime}=$ effective vertical stress and $\phi^{\prime}=$ effective angle of internal friction of the soil.

The amount of radiation damping during soil yielding is still not known but several researchers have shown that it is far less than the value obtained from the elastic assumption. Nogami (1987) compared numerical results obtained from his model with field tests and concluded that neglecting the gaps due to soil yielding at the pile-soil interface results in an overestimation of damping and an underestimation of pile deflection. Using centrifuge tests, Chako (1995) showed that the elastic formulation of radiation damping is valid only during small amplitude shaking and is excessive when large displacements due to soil yielding occurs. Therefore in the present analysis the effect of radiation damping is neglected during soil yielding.

\section{Comparison with Centrifuge Data}

For the method described in the previous section, a computer program based on the $\mathrm{C}$ language has been developed and the ability of the method to simulate pile behavior in liquefying soil has been demonstrated by comparing with centrifuge tests performed by Wilson et al. (1999) and Abdoun et al. (1997).

For the centrifuge test performed by Wilson et al. (1999), the soil profile consisted of two horizontal layers of saturated, fine, uniformly graded Nevada sand. The $11.4 \mathrm{~m}$ thick dense lower layer had a relative density $\left(D_{r}\right)$ of $80 \%$ and the $9.1 \mathrm{~m}$ thick medium dense upper layer had a relative density of $55 \%$. The structural model consisted of a single pile supported structure and was equivalent to a steel pipe pile with a diameter of $0.67 \mathrm{~m}$ and wall thickness of $19 \mathrm{~mm}$. The pile extended $3.8 \mathrm{~m}$ above the ground surface and carried a superstructure load of $480 \mathrm{kN}$. The depth of pile embedment was about $15 \mathrm{~m}$.

Properties of Nevada sand with $D_{r}=55$ and $80 \%$ are given in Table 1, and the variation of shear modulus along the depth of the soil deposit is given by (Popescu and Prevost 1993)

$$
G_{s}=G_{0}\left(\frac{\frac{1+2 K_{0}}{3} \sigma_{v}^{\prime}}{p_{0}}\right)^{0.7} \mathrm{MPa}
$$

where $K_{0}=$ coefficient of lateral earth pressure at rest, $p_{0}=$ reference normal stress which is $100 \mathrm{kPa}$ for sand (Popescu and Prevost 1993), and $G_{0}=$ low strain shear modulus of the soil. 


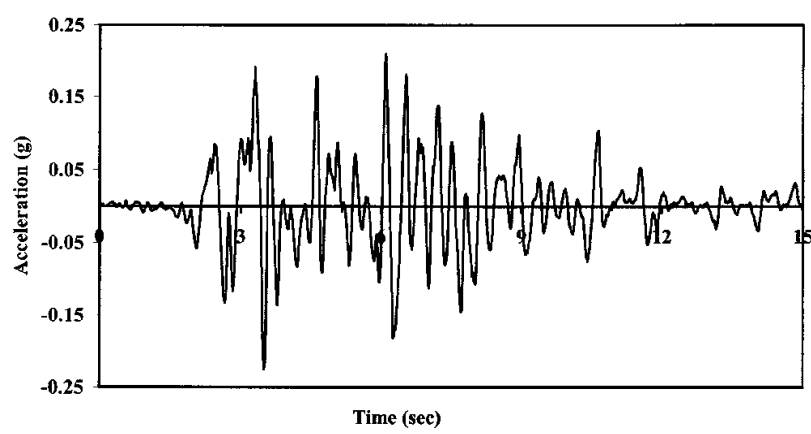

Fig. 3. Acceleration record of Kobe (1995) earthquake scaled to $0.22 \mathrm{~g}$ generated for the centrifuge test by Wilson et al. (1992)

This model was shaken with the acceleration record scaled to $0.22 g$ shown in Fig. 3, which is similar to the Kobe 1995 earthquake but with slight modifications to the frequency content. Fig. 4 shows the measured and computed pore pressure distribution close to the surface of the soil deposit, the superstructure acceleration, and the bending moment at $2.3 \mathrm{~m}$ depth. The recorded pore pressure distribution shows sharp pore pressure decreases due to soil dilation. In the acceleration record of the superstructure, sharp acceleration spikes can be seen corresponding to sharp pore pressure decreases. That means the pore pressure decrease due to soil dilation has increased the shear modulus of the soil and the corresponding increase in stiffness of the soil is sufficient to transmit large acceleration spikes through the ground to the superstructure during the seismic event.
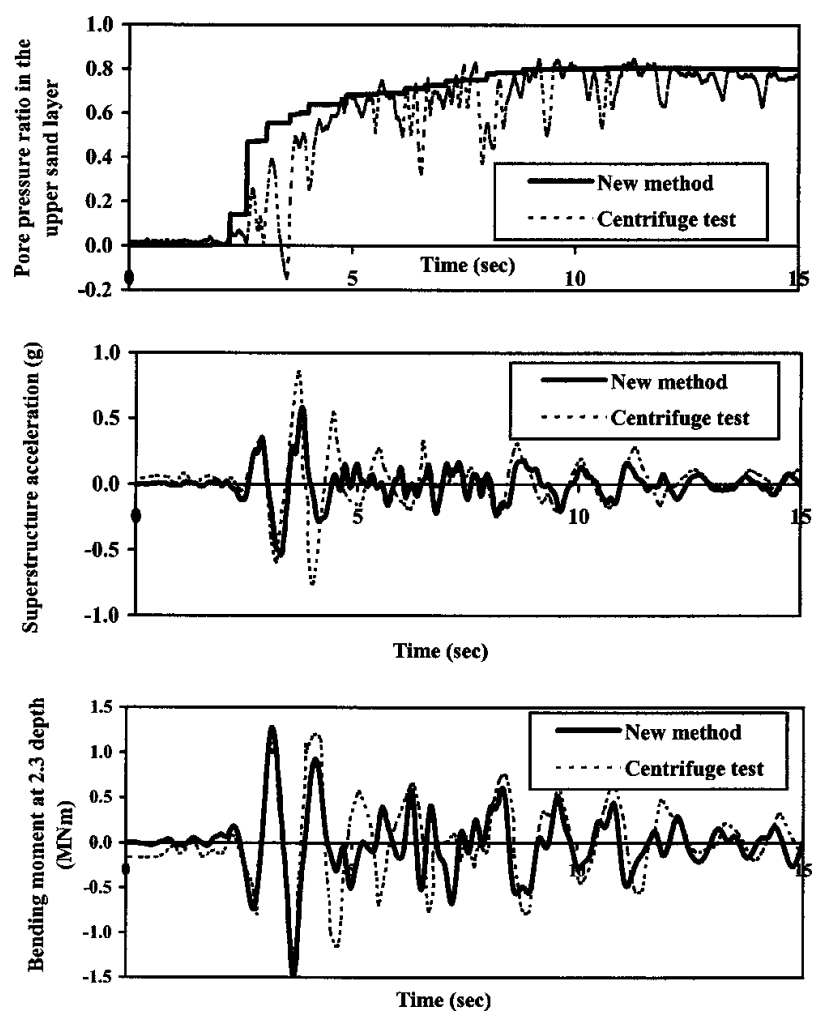

Fig. 4. Comparison of time histories of pore pressure in upper sand layer, superstructure acceleration and bending moment at $2.3 \mathrm{~m}$ depth with centrifuge test by Wilson et al. (1999)
In the numerical model, dilative behavior of the soil is not included. At present, it can model only pore pressure generation due to cyclic loading and dissipation within the soil due to vertical drainage. Therefore the sharp pore pressure decreases observed during the experiment cannot be modeled using the numerical model but the maximum pore pressure generated during the earthquake loading can be modeled and is in general agreement with the centrifuge test.

According to the superstructure acceleration distribution given in Fig. 4, results obtained from the numerical model agree well with the centrifuge test except at the point where pore pressure decreased to a negative value due to dilation of the soil. As discussed before, during the centrifuge test, pore pressure decrease due to dilation has increased the soil shear modulus. As a result, acceleration of the superstructure recorded during the centrifuge test is higher than that obtained from the numerical model, which does not take into account the dilative behavior of the soil.

In the design of pile foundations subjected to earthquake loading, the maximum bending moment developed is the most important design parameter. According to the bending moment distribution at $2.3 \mathrm{~m}$ depth given in Fig. 4, the maximum pile bending moment is corresponding to the sudden increase in pore pressure observed in the upper layer about $3.5 \mathrm{~s}$ after the application of earthquake loading. Since the present numerical model can simulate pore pressure generation reasonably well, the maximum bending moment obtained from the numerical model agrees well with the maximum bending moment recorded during the centrifuge test. Therefore it can be concluded that the soil dilation does not have a significant influence on the pile bending moment in liquefying soil because the maximum bending moment generated in the pile is corresponding to the softening of the soil due to pore pressure increase. Pore pressure decrease due to soil dilation has a tendency to reduce the maximum pile bending moment. Softening of the soil caused by pore pressure increase can be seen in the bending moment and acceleration time histories as an increase in the fundamental period of the structure.

Fig. 5 shows the bending moment and pile displacement obtained about $11 \mathrm{~s}$ after commencement of the earthquake loading. It can be seen that the results obtained from the numerical model agree reasonably well with the values recorded during the centrifuge test despite the simplicity of the new method.

Next the centrifuge test carried out by Abdoun et al. (1997) has been simulated using the numerical model presented in a previous section. The model used for their centrifuge test consisted of three sand layers. The middle layer was a $6 \mathrm{~m}$ thick Nevada sand layer with relative density of $40 \%$. Properties for this sand are given in Table 1 . The two cemented sand layers at the top and bottom of the model were $2 \mathrm{~m}$ thick and pervious. The input acceleration record generated for the test was a sine wave with an amplitude of $0.25 \mathrm{~g}$ and frequency of $2 \mathrm{~Hz}$ over a period of $20 \mathrm{~s}$. In the numerical analysis, it was assumed that the pore pressures were generated only in the middle Nevada sand layer.

The cemented sand used for the centrifuge test has a cohesion of $0.65 \mathrm{MPa}$ but other properties are not available. Therefore it is assumed that the shear modulus of the cemented sand is 10 times as high as that of the Nevada sand layer at the middle and the density of the cemented sand is $2,500 \mathrm{~kg} / \mathrm{m}^{3}$.

During the centrifuge test, $11 \mathrm{~s}$ after the commencement of the test, the sine wave was applied. Fig. 6 shows the pore pressure ratio distributions at 7.8 and $6 \mathrm{~m}$ below the surface. Early liquefaction is observed in the numerical simulation as also found in the experiment, but the pore pressure ratios agree only during the 

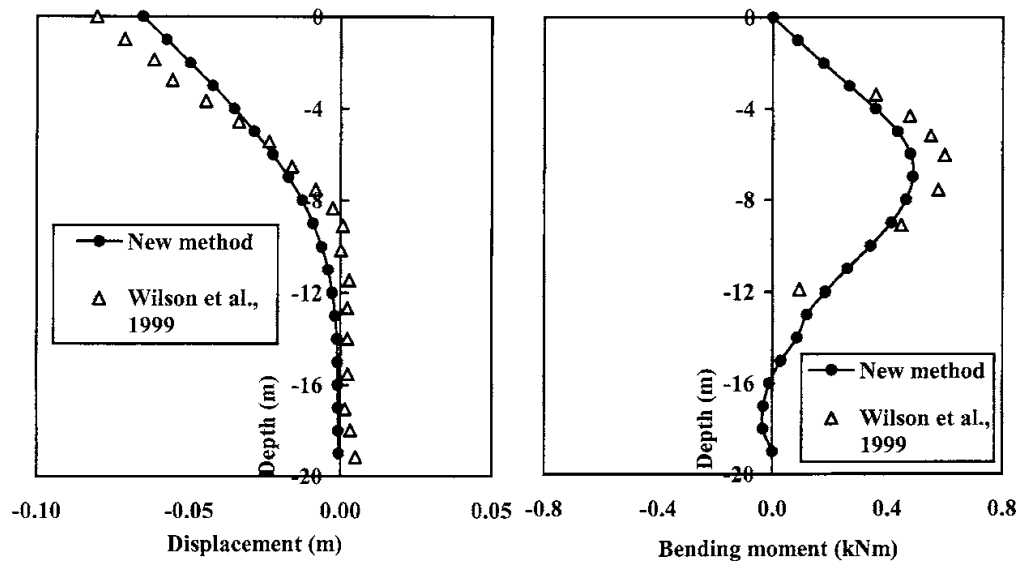

Fig. 5. Displacement and bending moment along the pile $11.2 \mathrm{~s}$ after application of the earthquake loading

period of shaking. In the numerical model, at the end of shaking, permeability of the soil was increased to a value four times higher than that used during the shaking, as proposed by Popescu and Prevost (1993), but the centrifuge test shows an even more rapid rate of decrease in pore pressure after the end of shaking. A similar behavior has been observed during the VELACS (verification of liquefaction analysis by centrifuge studies) project. If the pore pressure decrease occurs only due to pore pressure dissipation, it cannot happen at a fast rate similar to that shown in Fig. 6. The reason may be leakage of water along the walls of the laminar box and/or the instrumentation wires in the experiment.

Fig. 7 shows the lateral displacement along the depth of the soil deposit at 4, 14, and $24 \mathrm{~s}$ after the commencement of application of load. At 4 and $14 \mathrm{~s}$, displacement along the depth ob-
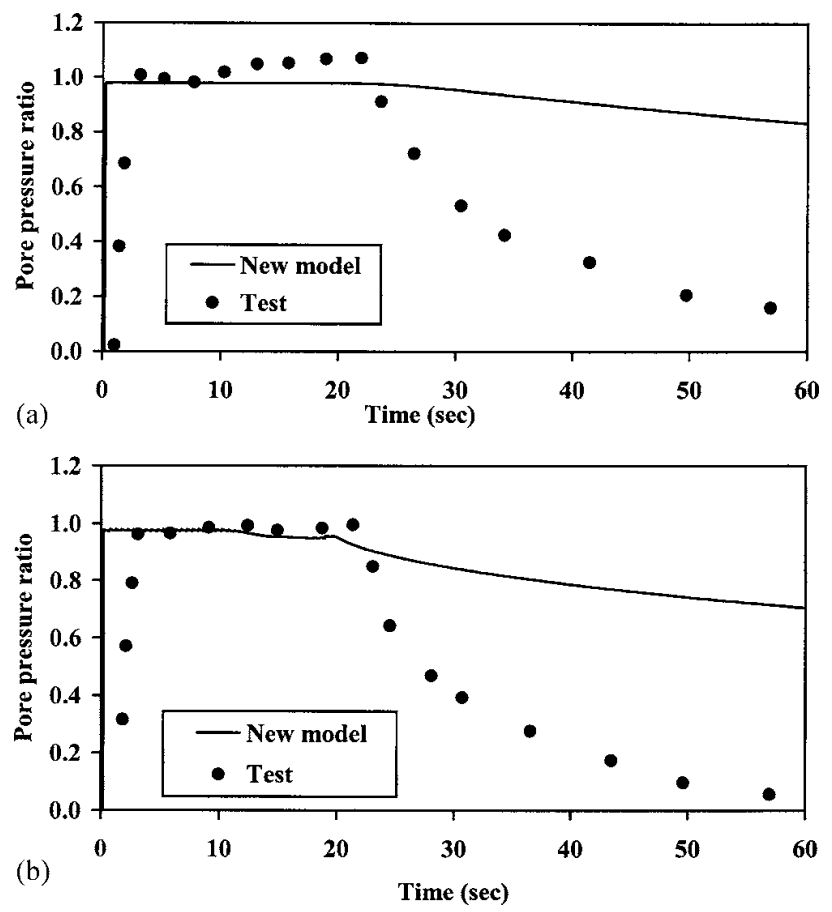

Fig. 6. (a) Comparison of pore pressure distribution at $7.8 \mathrm{~m}$ below the surface with the centrifuge test by Abdoun et al. (1997). (b) Comparison of pore pressure distribution at $6 \mathrm{~m}$ below the surface with the centrifuge test by Abdoun et al. (1997). tained from the numerical simulation matches well with the centrifuge data. However, at $24 \mathrm{~s}$, which is after the end of shaking, displacements given by the numerical model are larger than those observed during the centrifuge test. If the pore pressure ratios are compared at $6 \mathrm{~m}$ below the surface $24 \mathrm{~s}$ after shaking, numerical model and centrifuge test give pore pressure ratios of 0.9 and 0.6 , respectively. Therefore, $24 \mathrm{~s}$ after shaking, the soil behavior simulated using the numerical model shows more softening than the centrifuge test. Hence the numerical model gives higher displacements than the centrifuge model after the end of shaking, but during the period of shaking, displacements obtained from the numerical model agree well with the centrifuge test.

Figs. 8 and 9 show the pile bending moments obtained from the centrifuge test and the numerical model. Due to the discrepancy between pore pressure distributions obtained from the numerical model and the centrifuge test after the end of shaking, in Fig. 8, bending moment distributions at different depths were plotted only during the period of shaking. Again an excellent agreement can be seen between the measured and computed data. Therefore it can be concluded that the numerical model has the ability to simulate pile behavior reasonably well in liquefying soil.

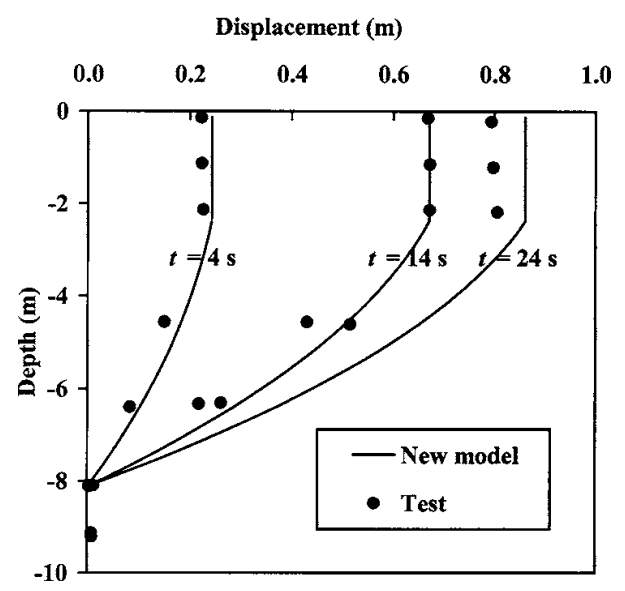

Fig. 7. Comparison of lateral displacement along depth at different times with centrifuge test by Abdoun et al. (1997) 

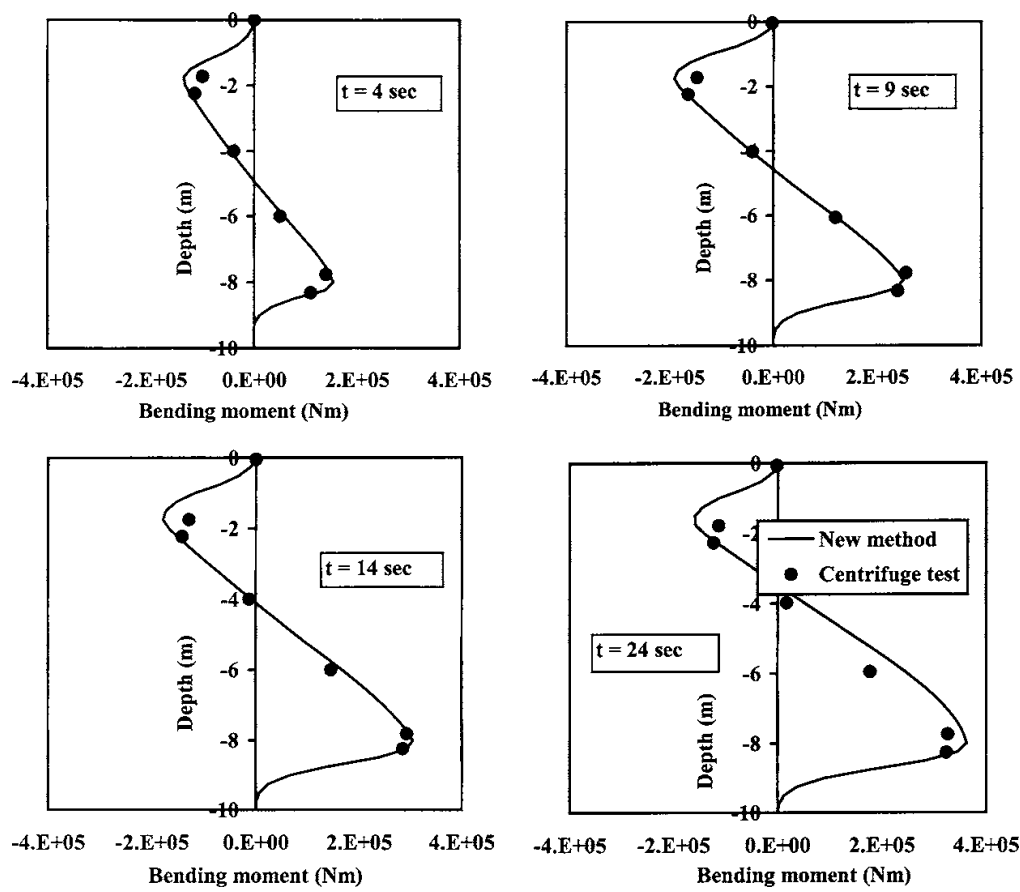

Fig. 8. Comparison of bending moment profiles with centrifuge test by Abdoun et al. (1997)

\section{Parametric Study}

In order to study the effects of soil liquefaction on pile performance, a parametric study has been carried out by varying geometric and material properties of the pile and soil, and the nature of the earthquake. The influence of pore pressure generation on pile performance is studied by comparing results obtained from a total stress analysis neglecting any pore pressure effects, with the results given by the effective stress analysis described in a previous section.

For all analyses presented, it is assumed that the soil follows the Mohr-Coulomb failure criterion, and the shear modulus of the soil is given by

$$
G_{s}=G_{0}\left(\frac{\frac{1+2 K_{0}}{3} \sigma_{v}^{\prime}}{p_{0}}\right)^{0.5}
$$

With a change in relative density, the shear modulus of the soil and friction angle have been changed. Results are presented for relative densities of $50,60,70,80$, and $90 \%$. For these relative densities, $G_{0}$ in Eq. (9) has been changed linearly from 30 to $50 \mathrm{MPa}$ and the effective friction angle of the soil has been changed linearly from 30 to $45^{\circ}$.

In all cases, the length of the pile is set to be equal to the depth of the soil deposit which overlays the bedrock. The soil has a density of $1,900 \mathrm{~kg} / \mathrm{m}^{3}$ and permeability of $10^{-4} \mathrm{~m} / \mathrm{s}$. It is assumed that the bedrock has a shear modulus of $3,500 \mathrm{MN} / \mathrm{m}^{2}$ and a density of $2,445 \mathrm{~kg} / \mathrm{m}^{3}$.

\section{Effect of Cap-Mass on Pile Performance}

Generally the superstructures supported by pile foundations are multi-degree of freedom systems. In the design of pile foundations, these multi-degree of freedom systems are commonly reduced to a single mass at the pile head, which is termed here the cap-mass, to simplify the analysis. When a pile carrying a cap-mass is subjected to seismic loading, the maximum bending moment generated in the pile has a contribution from the lateral displacements and curvatures imposed on a pile due to ground motion, which is known as kinematic bending and the inertial forces acting on the cap-mass, which represents the superstructure.

In this section, the significance of the bending due to inertia forces on piles founded in liquefying soil has been studied by comparing results obtained from a pile carrying a cap-mass and a pile without a cap-mass. In the actual situation, piles are often connected to the superstructure at the pile head. Therefore it is assumed that the pile head is restrained against rotation but free to move in the horizontal direction.

The cap-mass carried by a particular pile is determined based on the ultimate load carrying capacity of piles in sand. The input acceleration record used for the analysis is the 1995 Kobe earthquake record scaled to $0.15 \mathrm{~g}$. The analysis has been repeated for pile lengths of $15,25,35$, and $45 \mathrm{~m}$ and pile diameters of $0.3,0.6$, 0.9 , and $1.2 \mathrm{~m}$. The concrete piles used for the analysis have a density of $2,400 \mathrm{~kg} / \mathrm{m}^{3}$ and a Young's modulus of $3 \times 10^{4} \mathrm{MPa}$.

For the piles with and without cap-mass, the same free field ground displacements and degraded soil stiffness and strength have been applied during the pile analysis. The depths of the liquefied region obtained from the ground response analysis for each case are given in Fig. 10.

Fig. 11 shows the ratio of bending moments obtained for piles with and without cap-mass for different pile diameters, lengths, and soil relative densities. Since the pile head is restrained against rotation, in all cases, the maximum bending moment is developed at the pile head. According to Fig. 11, cap-mass, which represents the mass of the superstructure, has increased the maximum bending moment developed in the pile due to seismic loading. In some cases it is increased more than fivefold. Since the kinematic bending depends on the lateral displacements and curvatures imposed 

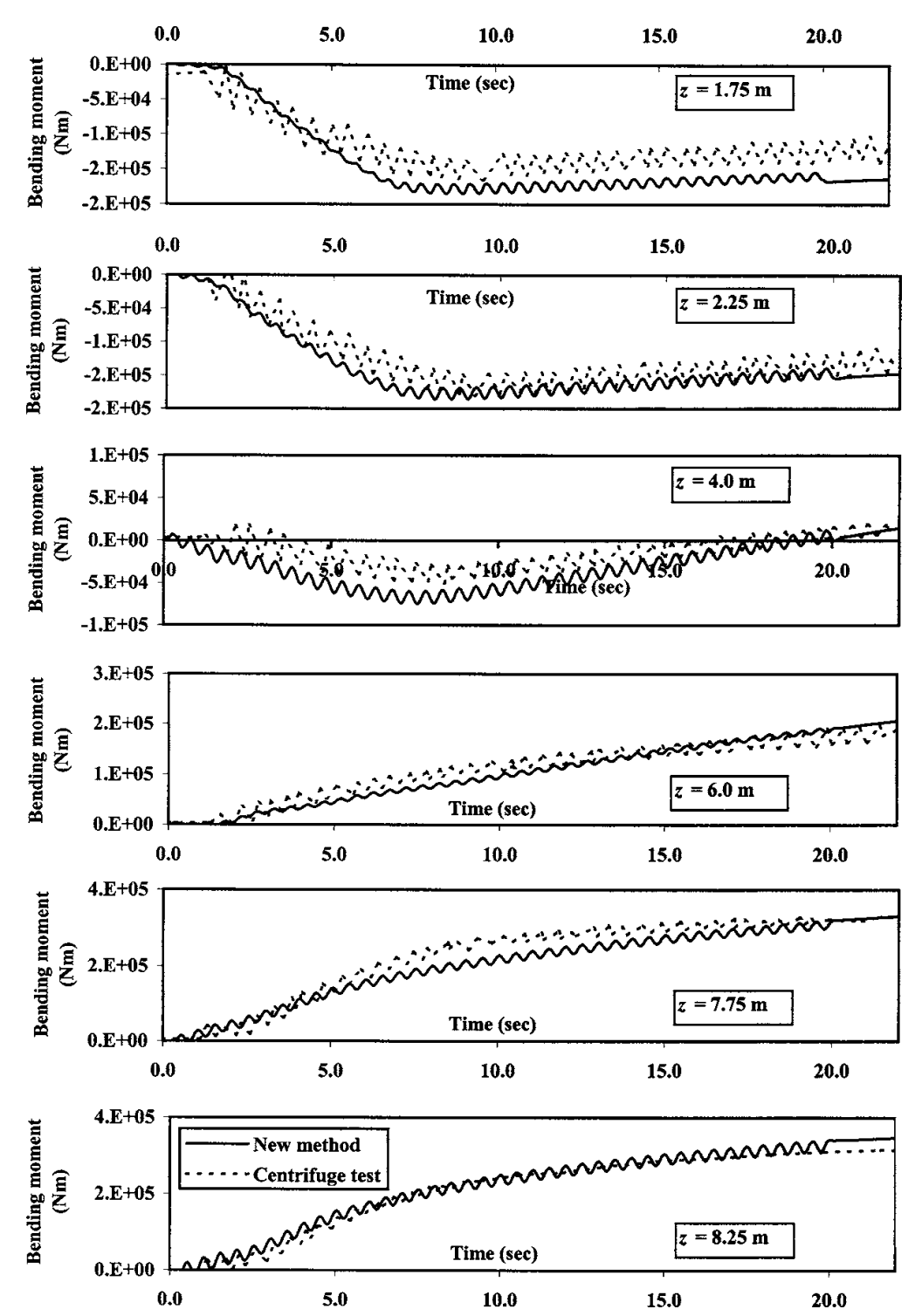

Fig. 9. Comparison of time histories of bending moments along pile with centrifuge data (Abdoun et al. 1997)

on the pile due to ground motion, it can be assumed that the same kinematic bending has been developed in piles with and without cap-mass. Therefore the increase in maximum bending moment indicates the significance of inertia force applied on piles carrying a cap-mass.

The inertia force at the pile head depends on the cap-mass and the acceleration of the superstructure. The increase in relative

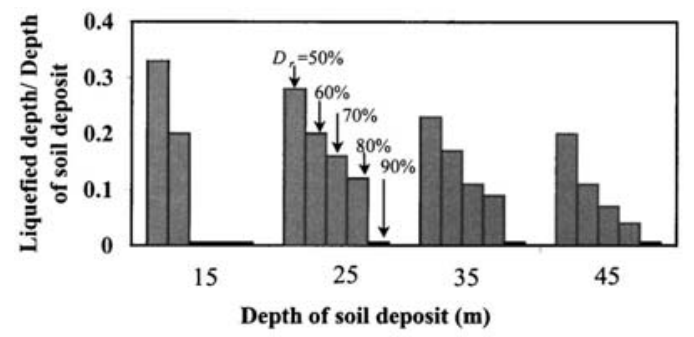

Fig. 10. Liquefied depth from the ground response analysis density will increase the cap-mass carried by a particular pile and reduce the degree of soil liquefaction, enabling large accelerations to be transmitted through the ground to the superstructure. Therefore the significance of cap-mass increases with the increase in relative density of the soil.

According to the parametric study, when the thickness of the liquefied region exceeds $30 \%$ of the thickness of the soil deposit, the bending moment ratio is less than 1.5 , irrespective of the diameter and length of the pile. Therefore it can be concluded that when the thickness of the liquefied region exceeds $30 \%$ of the total thickness of the soil deposit, an approximate value for the maximum pile bending moment induced in a pile carrying a capmass can be obtained by considering only the kinematic bending of the pile. However, for an accurate assessment of the maximum pile bending moment, the combined effect of inertial and kinematic bending should be taken into account.

Results obtained from the numerical study can be validated using the maximum bending moments recorded during the centrifuge test carried out by Abdoun et al. (2003) for $0.475 \mathrm{~m}$ diameter piles founded in two layer soil deposits. During these tests 


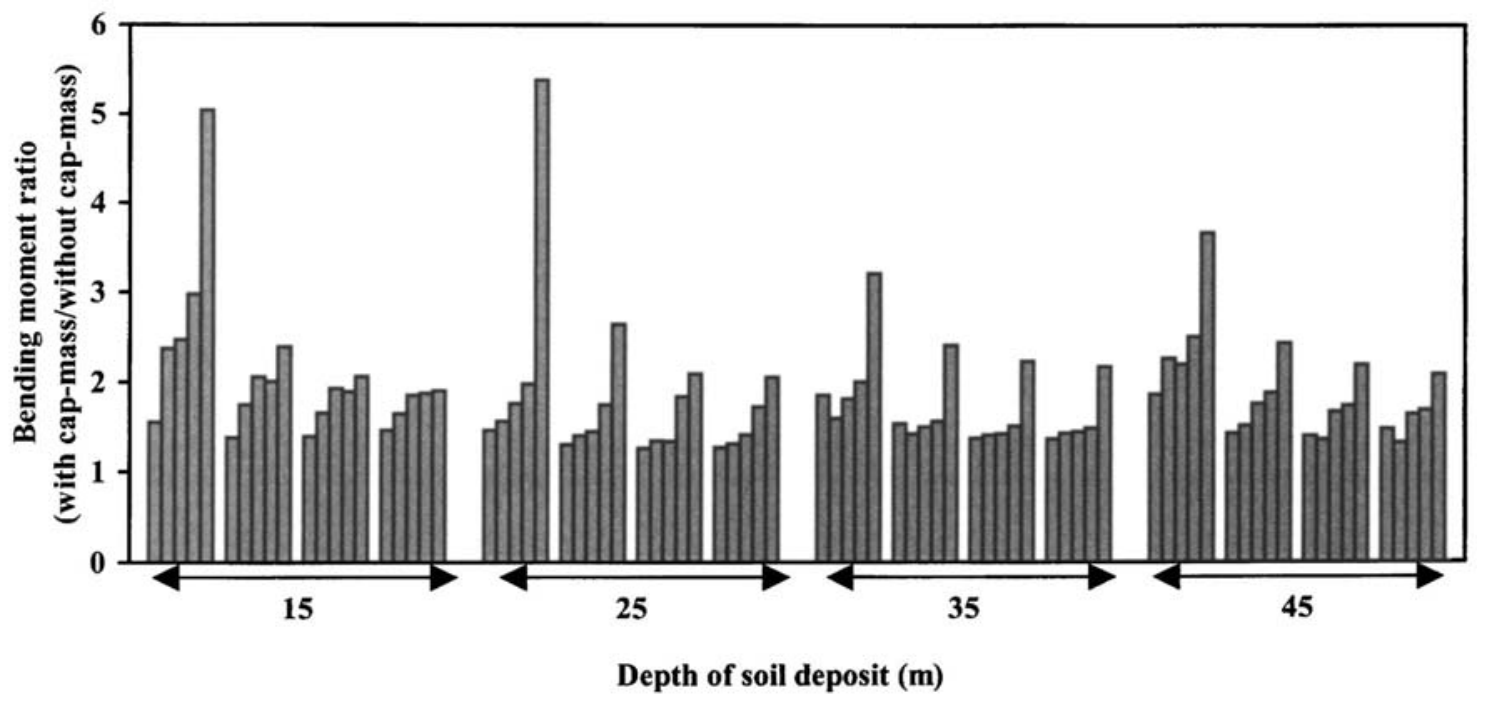

\section{Four main groups represent the depth of soil deposit $(15 \mathrm{~m}, 25 \mathrm{~m}, 35 \mathrm{~m}$ and $45 \mathrm{~m}$ ) and four sub-groups under each main group represent pile diameters $(0.3 \mathrm{~m}, 0.6 \mathrm{~m}, 0.9 \mathrm{~m}$ and $1.2 \mathrm{~m})$. Five columns under each sub-group represent relative densities $(50 \%, 60 \%, 70 \%, 80 \%$ and $90 \%)$.}

Fig. 11. Comparison of maximum pile bending moment with and without pile cap

\begin{abstract}
the top soil layer with relative density of $40 \%$ liquefied and the thickness of the liquefied region is about $75 \%$ of the total thickness of the soil deposit. These tests have been carried out for free-head piles, where the maximum bending moment is recorded at the interface between the liquefied and nonliquefied soil layers. For piles with and without cap-mass the maximum bending moments recorded during the centrifuge tests are, respectively, 170 and $113 \mathrm{kN} \mathrm{m}$, which results in a bending moment ratio of 1.5 .
\end{abstract}

\section{Effect of Pore Pressure Generation on Pile Performance}

Although numerical methods have been developed to obtain pile performance under earthquake loading, in many of them, the effect of soil strength and stiffness degradation due to pore pressure generation and subsequent soil liquefaction has not been incorporated (e.g., Kavvadas and Gazetas 1993; Norris 1994; El Naggar and Novak 1996; and Tabesh and Poulos 2001). Therefore, in many instances, pile design is based on the maximum bending moments and shear forces calculated assuming soil as a linear elastic material or a nonlinear material neglecting strength and stiffness degradation due to pore pressure generation. Therefore, in this section, results obtained from the effective stress analysis described in a previous section have been compared with a total stress analysis neglecting any pore pressure effects but incorporating the nonlinear behavior of the soil.

Before going into the details of pile behavior, it is important to study the influence of pore pressure generation on ground motion, which controls the kinematic bending of the pile. Fig. 12 shows the ratio of maximum ground displacement, which occurs at the ground surface, obtained from effective and total stress analyses. It can be seen that in some cases, the maximum ground displacement from the effective stress analysis is more than four times that given by the total stress analysis.
Fig. 13 shows the ratio between the effective and total stress analyses for maximum pile bending moment, relative displacement, pile head acceleration, and shear force. Piles carrying a cap-mass have been used for the analysis to incorporate the superstructure load transferred to the piles. As before, it is assumed that the pile head is restrained against rotation but free to move in the horizontal direction.

In all cases, inclusion of pore pressure generation has increased the maximum relative displacement and the bending moment developed at the pile head. In many cases, the maximum pile head acceleration has decreased when pore pressure effects are included. This happens due to softening of the soil, i.e., softening of the soil will increase the lateral ground displacements imposed on the pile and it smoothes high frequency peaks and troughs in the pile head acceleration. Therefore it can be con-

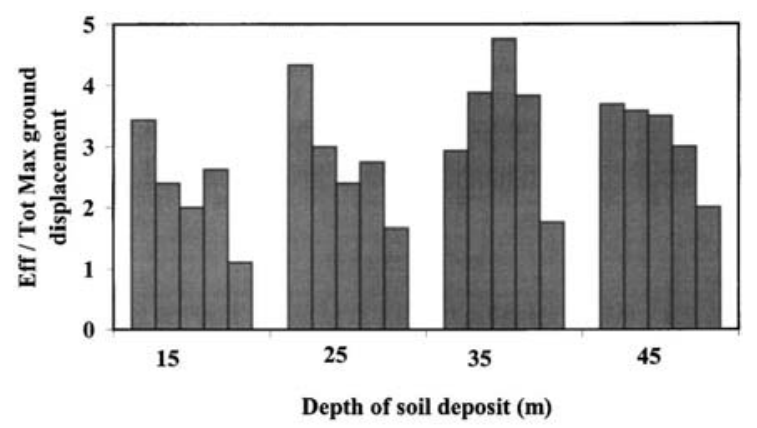

Fig. 12. Comparison of maximum ground displacement obtained from effective and total stress analyses 

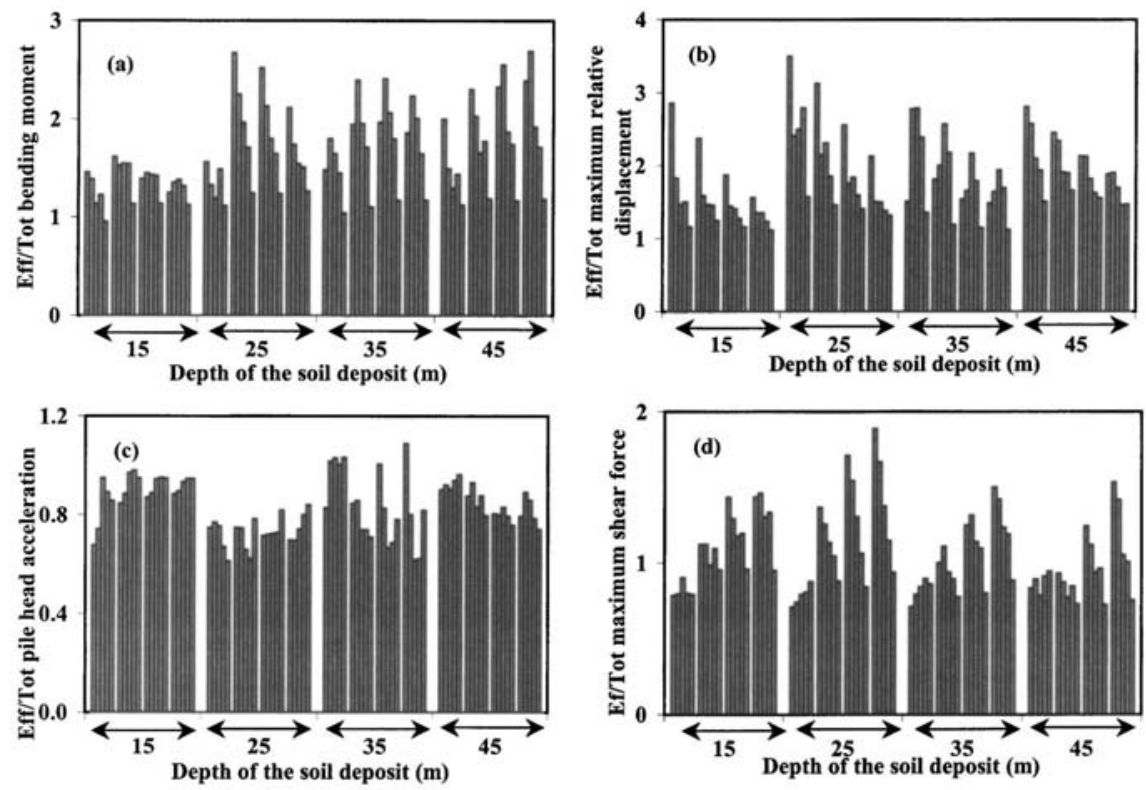

Four main groups represent the depth of soil deposit (15m, 25m, 35m and $45 \mathrm{~m}$ ) and four sub-groups under each main group represent pile diameters $(0.3 \mathrm{~m}, 0.6 \mathrm{~m}, 0.9 \mathrm{~m}$ and $1.2 \mathrm{~m})$. Five columns under each sub-group represent relative densities $(50 \%, 60 \%, 70 \%, 80 \%$ and $90 \%)$.

Fig. 13. Comparison of results obtained from the effective stress and total stress analyses

cluded that when pore pressure generation is taken into account the bending due to kinematic forces is more significant than the bending due to inertia forces.

Although maximum pile bending moment develops at the pile head, maximum shear force shown in Fig. 13(d) does not develop at the pile head in all cases. However, it develops within the top $25 \%$ of the pile length. A close examination of Fig. 13(d) shows that in some cases inclusion of pore pressure generation increases the maximum shear force developed in the pile while in others, it lessens the maximum shear force.

If the maximum shear force is developed at the pile head, the inertia force at the pile head (cap-mass $\times$ pile head acceleration) controls the shear force. Therefore the maximum shear force is reduced when the pore pressure effects are included. For other cases, kinematic forces due to large soil displacements caused by pore pressure generation and subsequent softening of the soil have a more significant influence than the inertia force at the pile head. Therefore when pore pressure generation is taken into account, the maximum shear force developed in the pile increases.

In the total stress analysis, although pore pressure generation is not incorporated, softening of the soil will occur due to soil yielding. Therefore, when there is no liquefaction, the maximum bending moment and shear force obtained from effective and total stress analyses are nearly the same. This can be seen in Figs. 13(a and d) when the relative density of the soil is $90 \%$. Therefore, when there is no liquefaction, maximum bending moment and shear force developed in a pile can be obtained from a total stress analysis, which takes into account the nonlinear behavior of the soil. However, if there is liquefaction, an effective stress based ground response analysis should be carried out to determine the maximum bending moment and shear force developed in the pile.

\section{Effect of Nature of Earthquake}

The nature of the earthquake ground motions on the significance of pore pressure generation has been studied by comparing the ratio of maximum pile bending moments obtained from an effective stress and total stress analyses. Here the nature of the earthquake is characterized by the "Arias Intensity" and the natural (predominant) frequency of the earthquake record.

The earthquake records used for the analysis are given in Table 2 and all these records have been scaled to $0.1 g, 0.15 g$, and $0.2 g$. Each earthquake record has been applied to a $25 \mathrm{~m}$ long pile with $0.9 \mathrm{~m}$ diameter founded in soil with relative density of $50 \%$.

Fig. 14 shows the variation of bending moment ratio with the Arias Intensity (Arias 1970) given by

$$
\text { Arias Intensity }=\frac{\pi}{2 g} \int_{0}^{T_{d}}(a c c)^{2} d t
$$

where $a c c=$ input acceleration at the level of bedrock at any time $t$ and $T_{d}=$ duration of the earthquake.

According to Fig. 14, there is a critical value of Arias Intensity and in this case it is about $0.06 \mathrm{~m} / \mathrm{s}$. When the Arias Intensity is less than the critical value, the maximum bending moments obtained from the effective and total stress analyses are nearly the same. Therefore a total stress analysis can be carried out to determine the maximum bending moment developed in the pile. Beyond the critical value, the scatter between results is very large and bending moment ratio varies between one and four. Therefore it can be concluded that there is no unique relationship between the Arias Intensity and the bending moment ratio when the Arias intensity of the earthquake ground motion exceeds the critical value. 
Table 2. Arias Intensity $(0.1 \mathrm{~g})$ and Natural Frequency of Different Earthquake Records and Bending Moment Ratio Obtained from the Numerical Model at $0.1 \mathrm{~g}$

\begin{tabular}{|c|c|c|c|}
\hline Earthquake & $\begin{array}{c}\begin{array}{c}\text { Arias Intensity } \\
(\mathrm{m} / \mathrm{s})\end{array} \\
\text { Maximum acceleration }=0.1 \mathrm{~g}\end{array}$ & $\begin{array}{c}\text { Natural } \\
\text { frequency } \\
\text { (cycles/s) }\end{array}$ & $\begin{array}{c}\text { Bending } \\
\text { moment ratio } \\
\text { (effective/total) }\end{array}$ \\
\hline Kobe-1995 & 0.106 & 3.333 & 1.37 \\
\hline Taft & 0.170 & 3.350 & 1.28 \\
\hline Loma-Prieta & 0.117 & 3.150 & 1.36 \\
\hline Pasadena & 0.243 & 2.067 & 1.74 \\
\hline El-Centro & 0.183 & 3.117 & 1.87 \\
\hline Niigata & 0.128 & 1.958 & 1.6 \\
\hline Whittier Narrows & 0.055 & 5.792 & 1.03 \\
\hline Melendy Ranche & 0.016 & 3.650 & 1.05 \\
\hline Meckering & 0.016 & 13.714 & 1.03 \\
\hline Cadoux & 0.004 & 14.111 & 1.0 \\
\hline Superstition Hill & 0.126 & 8.667 & 1.1 \\
\hline Northridge & 0.108 & 2.140 & 1.63 \\
\hline Newcastle-1989 & 0.087 & 1.472 & 1.45 \\
\hline Newcastle-1994 & 0.077 & 2.175 & 1.31 \\
\hline Oolong & 0.013 & 14.917 & 1.0 \\
\hline Tenant Creek & 0.008 & 19.500 & 1.02 \\
\hline Gunjung & 0.068 & 3.875 & 1.28 \\
\hline Saitama & 0.255 & 1.367 & 3.18 \\
\hline New Zealand-1973 & 0.113 & 4.950 & 1.11 \\
\hline Iran & 0.145 & 4.732 & 0.92 \\
\hline San Fernando & 0.132 & 4.620 & 0.98 \\
\hline Tomako & 0.085 & 7.267 & 0.89 \\
\hline Miyagi & 0.163 & 3.360 & 1.56 \\
\hline Tangshan & 0.355 & 3.043 & 1.73 \\
\hline Elmore Ranche & 0.149 & 5.917 & 1.1 \\
\hline
\end{tabular}

In Fig. 14, the maximum value of bending moment ratio is four and it corresponds to Arias intensity of $0.5 \mathrm{~m} / \mathrm{s}$. Beyond this value, bending moment ratio starts to decrease with increasing Arias intensity. Although the total stress analysis does not take into account any pore pressure effects, with the increase in intensity of the earthquake motion, softening of the soil due to yielding occurs. Therefore an increase in bending moment is observed in the total stress analysis. As a result, the bending moment ratio has decreased for cases with large Arias Intensity.

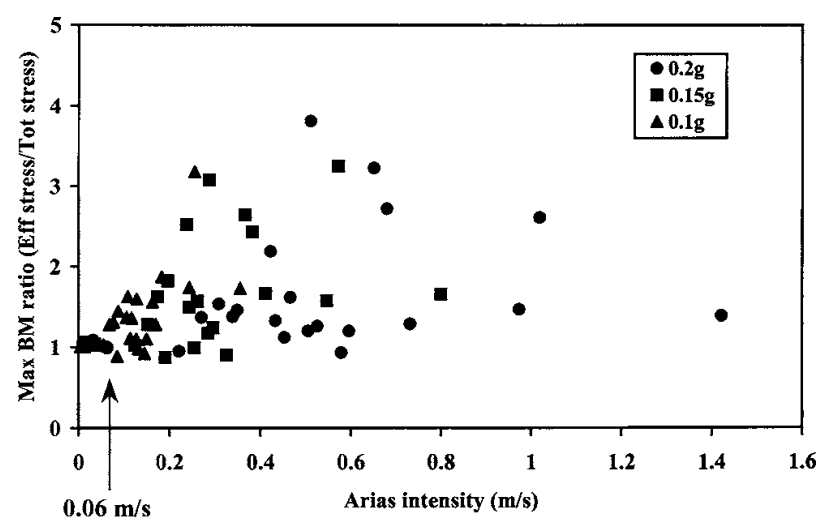

Fig. 14. Variation of maximum bending moment ratio obtained from effective and total stress analyses with Arias Intensity
Fig. 15 shows the variation of bending moment ratio with the natural (predominant) frequency of the earthquake record. Although the bending moment ratios have been plotted for different acceleration levels, the natural (predominant) frequency of the earthquake does not change with the acceleration level of the earthquake. According to Fig. 15, when the natural frequency of the earthquake exceeds 3.5 cycles/s, maximum bending moment obtained from the effective and total stress analyses are nearly the

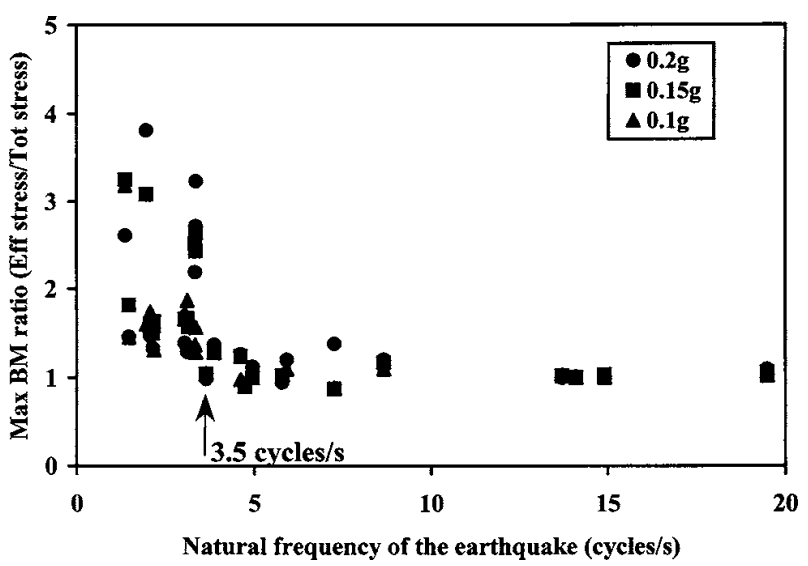

Fig. 15. Variation of maximum bending moment ratio obtained from effective and total stress analyses with the natural frequency of the earthquake 
same. Also, beyond $3.5 \mathrm{cycles} / \mathrm{s}$, the maximum bending moment ratio does not depend on the maximum acceleration level of the earthquake. It varies only with the natural (predominant) frequency of the earthquake. However, when the natural frequency of the earthquake is less than $3.5 \mathrm{cycles} / \mathrm{s}$, the increase in maximum bending moment developed in a pile due to stiffness and strength degradation is substantial.

From Fig. 15 and Table 2, it can be seen that when the natural frequency is greater than 3.5 cycles/s, in all cases the bending moment ratio is approximately 1 . However, with the Arias Intensity, bending moment ratio does not show such a unique relationship beyond the critical value. Although the bending moment ratio is approximately 1 for all cases with Arias Intensity less than $0.06 \mathrm{~m} / \mathrm{s}$, Elmore Ranche with Arias Intensity of $0.149 \mathrm{~m} / \mathrm{s}$ also gives a bending moment ratio of 1.1. Therefore the natural frequency of an earthquake can be considered as an important parameter in characterizing the nature of an earthquake on the pile behavior.

\section{Soil Liquefaction in Layered Soil Deposits}

In previous sections, uniform soil deposits with the same relative density have been studied using piles carrying a cap-mass with rotational restraint at the pile head. In all cases, the maximum bending moment occurred at the pile head. To study the pile performance in layered soil deposits, a two-layer soil deposit with a liquefying and a nonliquefying soil layer is considered. The dense nonliquefying soil layer has a relative density of $90 \%$ and is overlain by a soft liquefying soil layer with a relative density of $50 \%$. By varying the thickness of the liquefying soil layer, for a $25 \mathrm{~m}$ deep soil deposit, the maximum positive and negative bending moment envelopes are examined for piles with diameters 0.3 and $0.9 \mathrm{~m}$ for three different boundary conditions at the pile head: (1) free-head pile; (2) fixed-head pile; and (3) pile carrying a capmass with rotational restraint at the pile head. In all cases, the thickness of the nonliquefying layer equals the depth of soil deposit $(H)$ minus thickness of the liquefying layer $\left(h_{L}\right)$.

Fig. 16 shows maximum positive and negative bending moment envelopes for the $0.9 \mathrm{~m}$ diameter pile when the thickness of the upper liquefying soil layer is $4,8,12$, and $16 \mathrm{~m}$. When the thickness of the liquefying layer exceeds one-third of the total thickness of the soil deposit, the bending moment at the interface between liquefying and nonliquefying layers given by all three cases are the same. When the pile head is free, irrespective of the thickness of the liquefying layer, the maximum bending moment develops at the interface. For a fixed-head pile, maximum bending moment develops at the interface if the thickness of the liquefying layer is greater than one-third and less than two-thirds of the total thickness of the soil deposit. When the thickness of the liquefying layer lies outside this range, the maximum bending moment develops at the pile head. When the pile carries a capmass, which is based on the ultimate load carrying capacity of the pile, and with rotational restraint at the pile head, the maximum bending moment always develops at the pile head.

Dobry and O'Rourke (1983) and Nikolaou et al. (2001) proposed simple models to obtain kinematic pile bending moments, which neglects the contribution of inertia forces from the superstructure towards pile bending moments, at the interface between soil layers with stiffness contrast. Dobry and O'Rourke (1983) modeled the pile as a beam on a Winkler foundation and derived an expression for the pile bending moment at the interface as
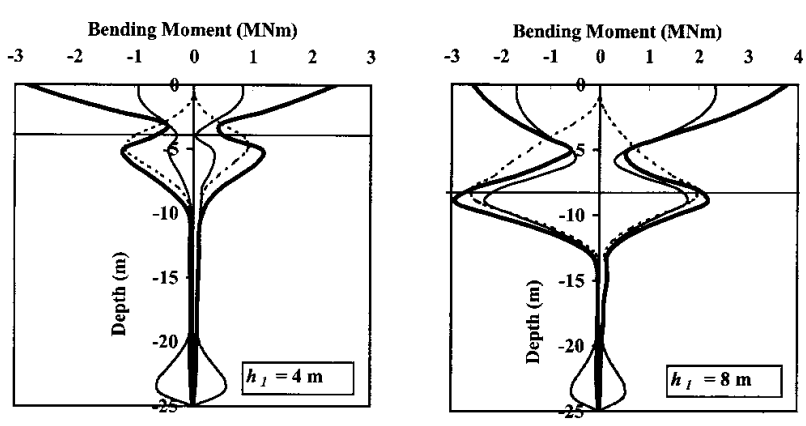

Bending Moment (MNm)

Bending Moment (MNm)

$\begin{array}{lllllllll}-4 & -3 & -2 & -1 & 0 & 1 & 2 & 3 & 4\end{array}$
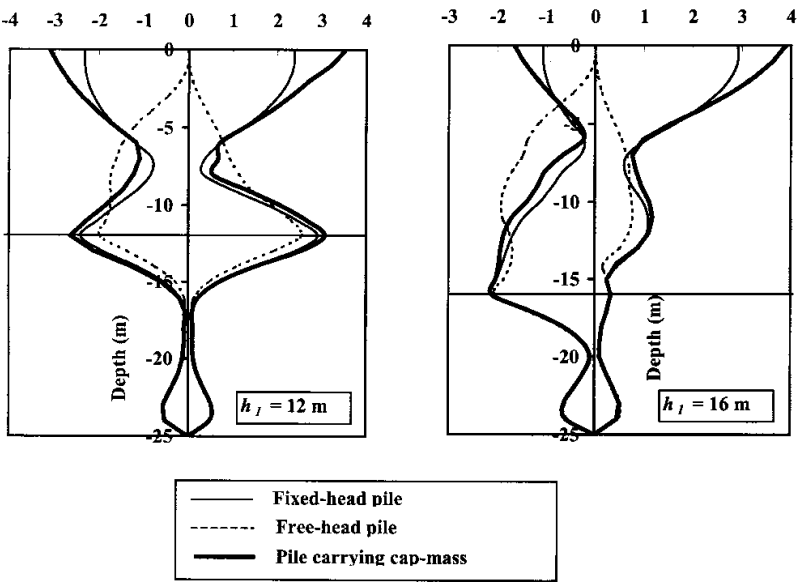

Fig. 16. Bending moment envelopes for a $0.9 \mathrm{~m}$ diameter pile in nonhomogeneous soil

$$
M=1.86(E I)^{3 / 4}\left(G_{1}\right)^{1 / 4} \gamma_{1} F\left(G_{2} / G_{1}\right)
$$

where $E=$ Young's modulus of pile material, $I=$ moment of inertia of pile, $G_{1}$ and $G_{2}=$ shear moduli of soil on either side of the interface with $G_{1}$ being the shear modulus of the weaker soil, $\gamma_{1}=$ free field shear strain corresponding to the weaker soil stratum, and $F\left(G_{2} / G_{1}\right)$ =function depending on $G_{1}$ and $G_{2}$.

Although Eq. (11) is derived for nonliquefying soil layers with stiffness contrast, here it is applied for a two-layer soil deposit when the weaker soil layer liquefies. Table 3 summarizes the results obtained from Eq. (11) and the finite element model described in a previous section. The shear modulus of the liquefied soil is calculated by limiting the effective stress level of the liquefied soil to $2 \%$ of the initial effective overburden pressure. It can be seen that this model overpredicts the bending moment developed at the interface when it is applied to a two-layer soil deposit with a liquefying soil layer. By applying the DobryO'Rourke (1983) model for nonliquefying soil layers with stiffness contrast, Nikolaou et al. (2001) also showed that it overpredicts bending moment at the interface.

Since the Dobry-O'Rourke (1983) model does not take into account the thickness of soil layers, natural frequency of the earthquake, and number of cycles of the earthquake, Nikolaou et al. (2001) proposed another model by taking into account those factors, as shown below

$$
M=0.042 \tau_{c} d^{3} \eta\left(\frac{L}{d}\right)^{0.30}\left(\frac{E_{p}}{E_{1}}\right)^{0.65}\left(\frac{V_{2}}{V_{1}}\right)^{0.50}
$$

where $d=$ pile diameter, $L=$ pile length, $E_{1}$ and $V_{1}=$ respectively, Young's modulus and shear wave velocity of the upper soil layer, $V_{2}=$ shear wave velocity of the lower soil layer, $\eta=$ reduction 
Table 3. Comparison of Numerical Model with Simple Design Methods Available for Layered Soil Deposits with Stiffness Contrast

\begin{tabular}{|c|c|c|c|c|c|c|c|c|c|}
\hline \multirow[b]{3}{*}{$\begin{array}{l}D \\
(\mathrm{~m})\end{array}$} & \multirow[b]{3}{*}{$\begin{array}{l}h_{L} \\
(\mathrm{~m})\end{array}$} & & \multicolumn{3}{|c|}{$\begin{array}{l}\text { Maximum BM from nonlinear } \\
\text { effective stress based } \\
\text { dynamic FE analysis } \\
(\mathrm{MN} \mathrm{m})\end{array}$} & \multicolumn{4}{|c|}{$\begin{array}{l}\text { Pile bending moment at the interface from } \\
\text { simple design methods }(\mathrm{MN} \mathrm{m})\end{array}$} \\
\hline & & & \multirow[b]{2}{*}{$\begin{array}{l}\text { Free- } \\
\text { head } \\
\text { pile }\end{array}$} & \multirow[b]{2}{*}{$\begin{array}{l}\text { Fixed- } \\
\text { head } \\
\text { pile }\end{array}$} & \multirow[b]{2}{*}{$\begin{array}{l}\text { Pile } \\
\text { with } \\
\text { cap }\end{array}$} & \multirow[b]{2}{*}{$\begin{array}{c}\text { Dobry and } \\
\text { O'Rourke } \\
(1983)\end{array}$} & \multicolumn{2}{|c|}{$\begin{array}{l}\text { Nikolaou et al. } \\
\qquad(2001)\end{array}$} & \multirow[b]{2}{*}{$\begin{array}{l}\text { Abdoun et al. } \\
\qquad(2003)\end{array}$} \\
\hline & & & & & & & $\begin{array}{l}\text { Frequency } \\
\text { domain }\end{array}$ & $\begin{array}{c}\text { Time } \\
\text { domain }\end{array}$ & \\
\hline \multirow[t]{8}{*}{0.3} & 4.0 & Head & & 0.101 & 0.209 & & & & \\
\hline & & Interface & 0.133 & 0.103 & 0.137 & 0.363 & 0.045 & 0.028 & 0.025 \\
\hline & 8.0 & Head & & 0.115 & 0.205 & & & & \\
\hline & & Interface & 0.092 & 0.106 & 0.092 & 0.195 & 0.111 & 0.070 & 0.1 \\
\hline & 12.0 & Head & & 0.127 & 0.226 & & & & \\
\hline & & Interface & 0.157 & 0.157 & 0.157 & 0.159 & 0.085 & 0.054 & 0.222 \\
\hline & 16.0 & Head & & 0.117 & 0.208 & & & & \\
\hline & & Interface & 0.081 & 0.081 & 0.081 & 0.155 & 0.079 & 0.050 & 0.4 \\
\hline \multirow[t]{8}{*}{0.9} & 4.0 & Head & & 0.930 & 2.810 & & & & \\
\hline & & Interface & 1.150 & 0.319 & 1.180 & 9.793 & 0.876 & 0.552 & 0.076 \\
\hline & 8.0 & Head & & 2.330 & 3.780 & & & & \\
\hline & & Interface & 2.460 & 2.320 & 2.930 & 5.253 & 2.163 & 1.363 & 0.297 \\
\hline & 12.0 & Head & & 2.370 & 3.530 & & & & \\
\hline & & Interface & 2.540 & 2.910 & 3.070 & 4.291 & 1.643 & 1.035 & 0.667 \\
\hline & 16.0 & Head & & 2.920 & 3.890 & & & & \\
\hline & & Interface & 2.110 & 2.110 & 2.110 & 4.202 & 1.552 & 0.978 & 1.187 \\
\hline
\end{tabular}

factor applied to the maximum steady-state pile bending moment in the frequency domain to arrive at the corresponding peak value in the time domain, and $\tau_{c}=$ shear stress that is likely to develop at the interface.

The Kobe earthquake record used for the analysis is similar to the earthquake record given in Fig. 3. For the four soil deposits considered for the analysis given in Table 3, the natural periods vary from about 1.05 to $0.89 \mathrm{~s}$ and lie within the range of the predominant periods of the excitation. According to Fig. 3, the Kobe earthquake record has about 10 effective excitation cycles $\left(N_{c}\right)$. Therefore the frequency-to-time conversion factor $\eta$ is approximately

$$
\eta \approx 0.04 \times N_{c}+0.23=0.63
$$

Bending moments at the interface computed from the Nikolaou et al. (2001) model are given in Table 3. It can be seen that for some cases the bending moment at the interface calculated in the frequency domain, which gives the harmonic steadystate results, agrees with the results obtained from the numerical model described in a previous section, but for others, it underpredicts the bending moment at the interface. When the harmonic steady-state bending moments are converted to the time domain, for all cases, the Nikolaou et al. (2001) model underpredicts the bending moment at the interface. Although Eq. (12) was derived based on the results obtained from a beam on a Winkler foundation model, they performed dynamic finite element analyses neglecting the nonlinear behavior of soil and the pore pressure generation due to earthquake loading. Therefore it can be concluded that when the nonlinearity of the soil and pore pressure generation are significant, the bending moments are underpredicted by the Nikolaou et al. (2001) model.

Recently Abdoun et al. (2003) proposed a method to evaluate the maximum bending moment developed in piles founded in liquefying soil subjected to lateral spreading based on the bending moments recorded during centrifuge tests carried out for concrete piles in two- and three-layer soil deposits. Tests were carried out for free-head piles with and without cap-mass and maximum bending moment was developed at the boundary between the liquefied and nonliquefied layers. By calibrating centrifuge test data, they found that the lateral pressure applied over a unit area of pile by the liquefying soil is a constant over the depth. This constant is given as $10.3 \mathrm{kPa}$. If the depth of the liquefied region is $h_{L}$ in a two-layer soil deposit with liquefied and nonliquefied layers, the maximum bending moment at the interface is given by

$$
M_{\max }=10.3\left(\frac{h_{L}^{2} D}{2}+A_{c} h_{c}\right)
$$

where $D=$ diameter of the pile, $A_{c}=$ area of pile cap subjected to the pressure of the liquefied soil, and $h_{c}=$ distance from the boundary between the liquefied and nonliquefied regions and the center of the area of pile cap in touch with the liquefied soil. They concluded that the maximum bending moment predicted with this value is within $15 \%$ of the maximum bending moment recorded during the centrifuge tests.

Table 3 shows the maximum bending moment calculated from this method when the top and bottom layers of the soil deposit have relative densities of 50 and $90 \%$, respectively. When piles carry a cap-mass, it is assumed that the pile cap is not in contact with the liquefied soil, i.e., $A_{c}$ in Eq. (14) is zero. The soil layer at the top has been completely liquefied for all cases listed. The limit equilibrium method proposed by Abdoun et al. (2003) is based on the results obtained from centrifuge tests carried out for piles with diameter 0.27 and $0.35 \mathrm{~m}$ and when the thickness of the liquefied soil layer is $6 \mathrm{~m}$. When comparing the results obtained from the numerical model and the limit equilibrium method for different pile diameters, $D$, and depths of liquefied soil, $h_{L}$, only the case 
with $D$ and $h_{L}$ closest to the centrifuge test, i.e., $D=0.3 \mathrm{~m}$ and $h_{L}=8 \mathrm{~m}$, agrees well with the limit equilibrium method. For the other cases the maximum bending moment at the interface obtained from the present numerical model and the limit equilibrium method do not agree well. For example, when $D=0.9 \mathrm{~m}$ and $h_{L}=12 \mathrm{~m}$, the maximum bending moment at the interface obtained from the numerical model is five times larger than that obtained from the Abdoun et al. (2003) limit equilibrium method.

\section{Conclusions}

A numerical procedure has been described which can be used to simulate pile performance in liquefying soil. First an effective stress based ground response analysis is carried out. Second the resulting ground displacements and degraded soil stiffness are applied to the pile dynamically to obtain the pile performance in liquefying soil. The spring coefficients of the Winkler model are derived from the Mindlin's equation. Results obtained from two centrifuge tests are simulated from the new method and the close agreement between results given by the numerical model and the data recorded during the centrifuge tests demonstrate the ability of the new method to simulate pile behavior in liquefying soil.

Results are also presented from a parametric study by varying geometric and material properties of the pile and soil, and the nature of the earthquake. It is shown that the inclusion of a capmass can significantly increase the bending moment developed in a pile by increasing the inertia forces acting on the pile. The inclusion of pore pressure effects increases the bending moments and relative displacements of the pile but it reduces the maximum cap-mass acceleration. In some cases, the peak shear force developed in the pile increases due to the inclusion of pore pressure effects. In others, the inclusion of pore pressure reduces the peak shear force developed in the pile, due to the dependency of shear force on the cap-mass acceleration.

It is found that the Arias intensity and the natural frequency of an earthquake are important parameters in characterizing the influence of the nature of an earthquake on pile behavior. If the Arias intensity of the earthquake ground motion is less than $0.06 \mathrm{~m} / \mathrm{s}$, maximum bending moments obtained from total and effective stress analyses are nearly the same. However, beyond this critical value, the scatter between results is very large. If the natural frequency of the earthquake is greater than $3.5 \mathrm{cycles} / \mathrm{s}$, a total stress analysis can be carried out to determine the maximum bending moment developed in the pile. If the natural frequency of the earthquake is less than $3.5 \mathrm{cycles} / \mathrm{s}$, the maximum bending moment given by an effective stress analysis can be as high as four times that given by a total stress analysis.

If the soil deposit is nonhomogeneous and the liquefying soil layer is underlain by a nonliquefying soil layer, for free-head piles, irrespective of the thickness of the liquefying soil layer, the maximum bending moment is developed at the interface between two layers. When a pile carries a cap-mass, which is based on the ultimate load carrying capacity of the pile, and restrained against rotational motion at the pile head, the maximum bending moment always develops at the pile head. For a fixed-head pile, the maximum bending moment develops at the interface if the thickness of the liquefying layer is greater than one-third, and less than twothirds, of the total thickness of the soil deposit. When the thickness of the liquefying layer lies outside this range, the maximum bending moment develops at the pile head. When the thickness of the liquefying layer exceeds one-third of the total thickness of the soil deposit, bending moment at the interface does not depend on the boundary condition at the pile head.

Simple models available to obtain kinematic pile bending moments at the interface between two layers with stiffness contrast have been applied to the case of a nonhomogeneous soil deposit with a liquefying soil layer underlain by a nonliquefying soil layer. It is found that when the nonlinear behavior of soil and pore pressure generation are taken into account, these simple models cannot be applied to obtain consistently accurate values of the maximum bending moment at the interface.

\section{Acknowledgments}

This work is part of a project on "Design of Pile Foundations for Seismically Active Areas" funded by the Australian Research Council and this support is gratefully acknowledged. Also the writers would like to thank Dr. Daniel W. Wilson for providing data files of the centrifuge test and the reviewers for their valuable comments.

\section{References}

Abdoun, T., Dobry, R., and O'Rouke, T. D. (1997). “Centrifuge and numerical modelling of soil-pile interaction during earthquake induced soil liquefaction and lateral spreading." Observation and Modelling in Numerical Analysis and Model Tests in Dynamic SoilStructure Interaction Problems-Proc., Sessions held in Conjunction with Geo-Logan '97, Logan, Utah, 76-90.

Abdoun, T., Dobry, R., O’Rouke, T. D., and Goh, S. H. (2003). "Pile response to lateral spreads: Centrifuge modelling." J. Geotech. Geoenviron. Eng., 129(10), 869-878.

Arias, A. (1970). “A measure of earthquake intensity.” Seismic design for nuclear power plants, R. J. Hansen, ed., MIT Press, Cambridge, Mass.

Broms, B. B. (1964). "Lateral resistance of piles in cohesionless soils." J. Soil Mech. Found. Div., 90(3), 123-156.

Chako, M. J. (1995). "Analysis of dynamic soil-pile structure interaction." masters thesis, Department of Civil and Environmental Engineering, University of California, Davis.

Davis, R. O., and Berrill, J. B. (1998). "Energy dissipation and liquefaction at Port Island, Kobe.” Bull. New Zealand Nat. Soc. Earthquake Eng., 31, 31-50.

Dobry, R., and O'Rourke, M. J. (1983). "Discussion on 'Seismic response of end-bearing piles,' by R. Flores-Berrones and R. V. Whitman.” J. Geotech. Eng., 109(5), 778-781.

Dobry, R., Taboada, V., and Liu, L. (1995). "Centrifuge modelling of liquefaction effects during earthquakes." Proc., First Conf. on Earthquake Geotechnical Engineering, Tokyo, 1291-1324.

Douglas, D. J., and Davis, E. H. (1964). "The movement of buried footings due to moment and horizontal load and the movement of anchor plates." Geotechnique, 14, 115-132.

El Naggar, M. H., and Novak, M. (1996). "Non-linear analysis for dynamic lateral pile response." Soil Dyn. Earthquake Eng., 15(4), 233-244.

Finn, W. D. L., Thavaraj, T., and Fujita, N. (2001). "Piles in liquefiable soils: Seismic analysis and design issues." Proc., 10th Int. Conf. on Soil Dynamics and Earthquake Engineering, Philadelphia, 48.

Hamada, M., Sato, H., and Nakamura, T. (1994). "An experimental and numerical study on liquefaction-induced ground displacement." Proc., 5th US National Conf. on Earthquake Engineering, 4, 169-178.

Horikoshi, K., Tateishi, A., and Fujiwara, T. (1998). "Centrifuge modelling of a single pile subjected to liquefaction-induced lateral spreading." Soils Found., (Special Issue No. 2), 193-208.

Ishihara, K., and Towhata, I. (1982). "Dynamic response analysis of level 
ground based on the effective stress method." Soil mechanicstransient and cyclic loads, G. N. Pande and O. C. Zienkiewicz, eds., Wiley, New York, 133-172.

Ishihara, K., and Yamasaki, F. (1980). "Cyclic simple shear tests on saturated sand in multi-directional loading." Soils Found., 20(1), 45-59.

Joyner, W. B., and Chen, A. T. F. (1975). "Calculation of nonlinear ground response in earthquakes." Bull. Seismol. Soc. Am., 65(5), 1315-1336.

Kavvadas, M., and Gazetas, G. (1993). "Kinematic seismic response and bending of free-head piles in layered soils." Geotechnique, 43(2), 207-222.

Liyanapathirana, D. S., and Poulos, H. G. (2002). "A numerical model for dynamic soil liquefaction analysis." Soil Dyn. Earthquake Eng., 22, 1007-1015

Mizuno, H., Sugimoto, M., Mori, T., Iiba, M., and Hirade, T. (2000). "Dynamic behaviour of pile foundation in liquefaction processShaking table tests utilising big shear box." Proc., 12th World Conf. on Earthquake Engineering, Auckland, New Zealand, Paper No. 1883.

Nakamura, T., Sugano, T., Oikawa, K., and Mito, M. (2000). "An experimental study on the pier damaged by 1995 Hyogoken-Nanbu earthquake." Proc., 12th World Conf. on Earthquake Engineering, Auckland, New Zealand, Paper No. 1038.

Nikolaou, S., Mylonakis, G., Gazetas, G., and Tazoh, T. (2001). "Kinematic pile bending during earthquakes: Analysis and field measurements." Geotechnique, 51(5), 425-440.

Nogami, T. (1987). "Prediction of dynamic response of nonlinear single pile by using Winkler soil model." J. Geotech. Eng., 114(9), $1512-1525$

Norris, G. M. (1994). "Seismic bridge pile foundation behaviour." Proc., Int. Conf. on Design and Construction of Deep Foundations, 1, 27-136.

Ohtomo, K. (1996). "Effects of liquefaction induced lateral flow on a conduit with supporting piles." Proc., 11th World Conf. on Earthquake Engineering, Paper No. 386.

Popescu, R., and Prevost, J. H. (1993). "Centrifuge validation of a numerical model for dynamic soil liquefaction." Soil Dyn. Earthquake
Eng., 12, 73-90.

Poulos, H. G. (1982). "Developments in the analysis of static and cyclic lateral response of piles." Proc., 4th Int. Conf. on Numerical Methods in Geomechanics, Canada, 1117-1135.

Sakajo, S., Chai, J. C., Nakajima, K., and Maeda, M. (1995). "Effect of group pile on liquefaction resistance of sandy ground." Proc., First Conf. on Earthquake Geotechnical Engineering, Tokyo, 755-760.

Shahrour, I., and Ousta, R. (1998). "Numerical analysis of the behaviour of piles in saturated soils under seismic loading." Proc., 11th European Conf. on Earthquake Engineering.

Tabesh, A., and Poulos, H. G. (2000). "A simple method for the seismic analysis of piles and its comparison with the results of centrifuge tests." Proc., 12th World Conf. on Earthquake Engineering, Auckland, New Zealand, Paper No. 1203.

Tabesh, A., and Poulos, H. G. (2001). "The effect of soil yielding on seismic response of single piles." Soils Found., 41(3), 1-16.

Tamura, S., Suzuki, Y., Tsuchiya, T., Fujii, S., and Kagawa, T. (2000) "Dynamic response and failure mechanisms of a pile foundation during soil liquefaction by shaking table test with a large scale laminar shear box." Proc., 12th World Conf. on Earthquake Engineering, Auckland, New Zealand, Paper No. 0903.

Wilson, D. W., Boulanger, R. W., and Kutter, B. L. (1999). "Lateral resistance of piles in liquefying sand." Geotechnical Special Publication No. 88, Proc., Analysis, Design, Construction and Testing of Deep Foundations, ASCE, Reston, Va., 165-179.

Wilson, D. W., Boulanger, R. W., and Kutter, B. L. (2000). "Observed seismic lateral resistance of liquefying sand." J. Geotech. Geoenviron. Eng., 126(10), 898-906.

Yasuda, S., Ishihara, K., Morimoto, I., Orense, R., Ikeda, M., and Tamura, S. (2000). "Large-scale shaking table tests on pile foundations in liquefied ground." Proc., 12th World Conf. on Earthquake Engineering, Auckland, New Zealand, Paper No. 1474.

Zheng, J., Susuki, K., and Ohbo, N. (1996). "Evaluation of sheet pile-ring countermeasure against liquefaction for oil tank site." Soil Dyn. Earthquake Eng., 15(6), 369-379. 